\title{
Notificaciones electrónicas judiciales: una aproximación a la reglamentación y uso en algunos países iberoamericanos*
}

Judicial Electronic Notifications: An Overview to the Regulation and Use in Some Ibero-American Countries

\author{
David Namen Baquero ${ }^{\mathrm{a}}$ \\ Universidad Externado de Colombia, Colombia \\ david.namen@uexternado.edu.co \\ ORCID: https://orcid.org/0000-0002-8253-6890
}

DOI: https://doi.org/10.11144/Javeriana.vj69.neja

Recibido: 18 Septiembre 2019

Aceptado: 18 Octubre 2019

Publicado: 15 Agosto 2020

\section{Resumen:}

Las notificaciones judiciales cumplen el propósito de darle a conocer la decisión que toma el juez frente a un asunto a las partes. Cada país tiene unas reglas específicas que varían conforme a la decisión que requiere ser notificada. Actualmente, la tecnología ha simplificado la labor del juez al permitir gestionar las notificaciones por medios electrónicos. El presente estudio busca analizar la situación de algunos países iberoamericanos en torno al uso de los recursos tecnológicos para gestionar notificaciones en el ámbito judicial. En la primera parte, se analiza en forma sucinta el marco normativo existente, y en la segunda, se hace una comparación de los elementos más destacados de cada país.

Palabras clave: notificaciones, medios electrónicos, plataformas, sistemas de autenticación, certificado electrónico.

\section{Abstract:}

Judicial notices serve the purpose of informing the parties of the decision the judge makes concerning a matter. Each country has specific rules that vary according to the decision that needs to be notified. Today, technology has simplified the judge's work by allowing notifications to be handled electronically. The present study seeks to analyze the situation of some Ibero-American countries regarding the use of technological resources to manage notifications in the judicial field. In the first part, the existing normative framework is briefly analyzed, and in the second, a comparison of the most outstanding elements of each country is made.

Keywords: notifications, electronic means, platforms, authentication systems, electronic certificate.

\section{Introducción}

Los avances tecnológicos han permeado considerablemente todas disciplinas del conocimiento, y el derecho no es la excepción. Cada vez es más frecuente el uso de los recursos tecnológicos que buscan simplificar la relación de los particulares con el Estado o dotarlos de herramientas alternativas que les permita la efectividad de sus derechos.

El derecho procesal no escapa a esta revolución tecnológica. Su disciplina muestra un catálogo amplio, desde la posibilidad de gestionar el expediente de manera electrónica, hasta la realización de audiencias a través de videoconferencias o la notificación de las providencias judiciales por medios virtuales. Frente a este último, la experiencia en la implementación de las notificaciones judiciales electrónicas ha sido disímil en muchos países, bien sea porque no disponen de la infraestructura para ello o porque sus cuerpos normativos aún no se ajustan a las realidades tecnológicas, o simplemente por la desconfianza que genera en algunos sectores estas comunicaciones y su autenticidad.

Legislaciones más avanzadas utilizan plataformas específicas que facilitan la comunicación entre los órganos judiciales y los intervinientes procesales. En otras dependencias que ya han iniciado su uso, las notificaciones electrónicas no se surten mediante un 'software,' 'aplicativo' o 'plataforma' especializada, sino

Notas de autor

\footnotetext{
${ }^{a}$ Autor de correspondencia. Correo electrónico: david.namen@uexternado.edu.co
} 
mediante el envío de correos electrónicos certificados por una entidad habilitada que hace constar la emisión y recepción de la comunicación.

El objetivo del presente artículo es describir los avances de algunos países iberoamericanos sobre la implementación de las notificaciones electrónicas en el ámbito judicial. La primera parte del documento condensa la normativa vigente de cada país, sus características más relevantes y su funcionamiento. La segunda, realiza una comparación de los elementos más destacados de cada país ${ }^{1}$.

\section{Las notificaciones electrónicas en Argentina, Brasil, Colombia, Costa Rica y Portugal}

\section{Argentina}

\section{Fundamentos normativos}

La experiencia en la República Argentina a nivel nacional ${ }^{2}$ con respecto a las notificaciones judiciales en formato electrónico se fundamenta en la Ley 26.685 de $2011^{3}$ e inicia formalmente con la Acordada 31 de $2011^{4}$ de la Corte Suprema de Justicia de la Nación (en adelante CSJN), a través de la cual se crea el domicilio electrónico y el Sistema de Notificaciones por Medios Electrónicos (en adelante SNE) 5 .

La Acordada 31 de 2011 se erige en el punto de partida y complementa con otras Acordadas ${ }^{6}$ que fijan paulatinamente las fases en la implementación de los recursos tecnológicos en el Poder Judicial Argentino.

La primera fase está constituida por la Acordada 3 de $2012^{7}$ que estableció de obligatoria aplicación el uso de los medios electrónicos a partir del 7 de mayo de 2012 para la tramitación de los escritos de queja ante la CSJN por denegación del recurso extraordinario, resueltos por los tribunales del Poder Judicial de la nación con asiento en la Ciudad de Buenos Aires y, también, para los recursos extraordinarios promovidos desde el primer día hábil posterior a la feria de enero de 2013.

La segunda fase se presenta con la Acordada 29 de $2012^{8}$, que extiende el uso de las notificaciones electrónicas a partir del primer día hábil posterior a la feria de enero de 2013, para todos recursos de queja provenientes de los tribunales del Poder Judicial de la Nación Argentina.

La tercera fase ocurre con la Acordada 35 de $2013^{9}$ que reconoce las ventajas de las dos fases anteriores y amplia el uso de las notificaciones electrónicas a todos los recursos ordinarios y los recursos de queja por denegación de aquellos, las denuncias por retardo o denegación de justicia y todas las actuaciones varias que se interpusieran a partir del 14 de octubre de 2013.

La cuarta fase la comprende la Acordada 36 de $2013^{10}$, que establece la obligatoriedad del sistema a todas las causas en las que interviene la Secretaria de Juicios Originarios de la CSJN a partir del 1 de noviembre de 2013.

La quinta fase también estaba prevista para el año 2013 con la Acordada $38^{11}$ y dispuso que, por la implementación paralela del Sistema de Gestión Judicial "lex 100", era imperativo extender el uso de las notificaciones electrónicas a las Cámaras Nacionales, Federales y a los Tribunales Orales, en dos etapas más.

Además de estas fases, la CSJN profiere otras dos acordadas relativas a las notificaciones electrónicas, la $11 / 2014$ y $3 / 2015^{12}$. La última es de gran importancia por cuanto establece la obligatoriedad de las notificaciones electrónicas a todos los procesos que se encontraban en trámite independientemente de su fecha de inicio. 
A este recuento normativo, se agrega la Resolución $2998 / 2014^{13}$, que dispone una excepción en el uso de las notificaciones electrónicas cuando se trate de letrados no videntes que alleguen el respectivo certificado de discapacidad.

\section{Aspectos notorios del sistema de notificación electrónica-SNE-argentino}

La implementación del SNE en Argentina se da a través de distintas fases, en cada una de las cuales, se extiende progresivamente a diferentes causas. Sin embargo, las características relevantes del sistema están descritas en la Acordada 31 de 2011, de las que se destacan las siguientes:

\section{Registro de usuarios y domicilio electrónico}

Para el uso del SNE, es menester contar con un registro previo. El registro se hace ante la Dirección de Sistemas de la CSJN, que suministra un código de usuario y una contraseña al interesado, con los que podrá ingresar al portal web. Debe resaltarse que después de haber realizado el registro, no se permiten notificaciones electrónicas por fuera del sistema, esto es el envío de correos electrónicos a cuentas privadas.

El anexo I de la Acordada 31/2011 detalla el registro. En concreto, el sistema reconoce dos clases de usuarios: externos e internos. Los primeros, comprende a los abogados, funcionarios del Ministerio Público y toda persona que litigue por propio derecho o en ejercicio de una representación legal. Los segundos, se integran por los funcionarios o empleados del tribunal. El proceso de registro requiere de un trámite virtual y otro presencial para los usuarios externos.

El trámite en línea se realiza a través de la página de la $\operatorname{CSJN}^{14}$ en el enlace de "notificaciones electrónicas" y luego "regístrese" ". A medida que se vaya completando el formulario, el sistema le solicitará al interesado sus datos personales, como nombres, apellidos, fecha de nacimiento, correo electrónico, una fotografía, número de matrícula profesional, DNI y una constancia de inscripción a la Clave única de Identificación Laboral y Tributaria (En adelante CUIL y CUIT, respectivamente). Al finalizar el formulario, se le enviará una constancia de preinscripción al usuario.

El trámite presencial es consecuencia del trámite en línea, y el inscrito debe presentarse dentro de los treinta (30) días siguientes al registro ${ }^{16}$ para el proceso de autenticación y validación de los documentos que ingresó en el portal web al momento de darse de alta. Este trámite se realiza ante cualquier juzgado o tribunal federal con sede en provincias, juzgados y tribunales federales y nacionales de la Ciudad Autónoma de Buenos Aires o en la Mesa General de Entradas de la CSJN. Constatados los documentos, se habilita su inclusión en el sistema y emite la constancia de acreditación de identidad y validación de documentos, como también su código de usuario. El sistema no requiere que el usuario disponga de la firma digital para el ingreso a la plataforma, basta con las credenciales que le son proporcionadas una vez finalizado el proceso de registro, pero sí es necesario que cuente con un certificado de firma digital para la posterior consulta de las notificaciones que se le vayan realizando. Respecto a los usuarios internos, el código de acceso se hará conforme a su incorporación en el Sistema de Gestión Judicial.

Por último, igualmente es requisito indispensable para el registro que el usuario tenga un domicilio electrónico, lo cual no es más que el código de usuario, correspondiente al CUIT/ CUIL (Clave Única de Identificación Tributaria y Clave Única de Identificación Laboral, respectivamente) que el titular diligenció al momento de realizar la inscripción. La obligación de constituir domicilio electrónico estaba prevista inicialmente para las causas que se tramitaban ante la CSJN. Sin embargo, a medida que se vino implementando el sistema y se fue extendiendo con las respectivas acordadas a otras causas, la carga de constituir domicilio electrónico también se amplió. ${ }^{17}$ 


\section{Providencias y plazos}

El artículo 3 de la Acordada 31 de 2011 dispone:

todas las notificaciones de providencias, resoluciones y sentencias que deban practicarse personalmente o por cédula se realizarán en el código de usuario que el beneficiario deberá haber constituido como domicilio electrónico. La notificación se considerará perfeccionada cuando esté disponible en la cuenta de destino; los plazos se computarán según la normativa procesal que corresponda. A fin de establecer el comienzo del plazo de la notificación, su fecha y hora será la del servidor y quedará registrada en la transacción ${ }^{18}$.

El prenotado artículo indica cuales notificaciones pueden hacerse mediante el SNE y establece que su perfeccionamiento se dará cuando esté disponible en el domicilio electrónico del destinatario. Esto significa que la notificación se produce desde el mismo instante en que se puede consultar para su lectura, con independencia del momento en que efectivamente el usuario ingresó y le dio apertura.

Para facilitar la labor al litigante, el SNE dispone de un "email de cortesía" que se trata de una comunicación informal, cuya finalidad es la de actuar como una alerta de que en el sistema se generó una actuación que debe ser atendida, pero que, en ningún caso, puede servir de pretexto para alegar que no se practicó debidamente la notificación. En cuanto al cómputo de los términos o plazos, la disposición remite al estatuto procesal pertinente, que, en este caso, se resume puntualmente a los artículos 152 y 156 del Código Procesal Civil y Comercial de la Nación ${ }^{19}$.

\section{Creación de la notificación por usuarios externos}

Con la Acordada 38 de 2013 se faculta a las partes para elaborar las notificaciones que sean de su competencia y que, grosso modo, consta de cinco pasos: (1) la elección del expediente, (2) definición del destinatario, (3) despacho a notificar, (4) adjuntos y (5) texto a notificar. Realizada la notificación, el sistema emite dos comunicaciones, una al sistema de gestión procesal 'lex 100' y la otra es un correo de "cortesía” a los destinatarios ${ }^{20}$.

\section{Mantenimiento del sistema}

El mantenimiento del sistema está en manos de la Dirección de Sistemas de la Corte Suprema de Justicia de la Nación, dentro de cuyas funciones debe garantizar la confidencialidad de la información que circula en el sistema, el soporte técnico del módulo web, la seguridad del sistema, la integridad de las notificaciones y la capacitación del personal, entre otras más, señaladas en el Anexo II de la Acordada 31 de $2011^{21}$.

\section{Brasil}

\section{Fundamentos normativos}

En Brasil, el uso de las notificaciones electrónicas en sede judicial inicia con la Ley 11.419 de $2006^{22}$ por la cual se reglamentó el proceso electrónico en todas las materias, desde la petición inicial hasta la resolución del mismo e introdujo los conceptos de "firma digital", "medio electrónico" y "transmisión electrónica".

La ley dedica el Capítulo II a las "Comunicaciones electrónicas de los Actos Procesales" (Da Comunicação Eletrônica Dos Atos Processuai) y menciona la posibilidad de la creación por los tribunales 
de un Diario de Justicia Electrónico (en adelante DJE), disponible en su portal web para notificar todas las actuaciones que emita, exceptuándose las que por su naturaleza sean personales.

La ley también facultó a los distintos órganos del poder judicial para crear sistemas de código abierto tendientes a la gestión procesal, incluyendo las notificaciones electrónicas. En virtud de esta facultad y en consideración a que Brasil es un estado federado, coexisten varios sistemas en la actualidad, ${ }^{23}$ cada cual, con una reglamentación específica, pero sujeta a las pautas comunes consagradas en la Ley 11.419 de 2006.

Sin embargo, a partir del año 2011, son notorios los esfuerzos del Consejo Nacional de Justicia de Brasil para implementar un solo sistema de tramitación electrónica en todo el territorio nacional. En efecto, la Resolución $185 / 2013^{24}$ ordena la implementación gradual y obligatoria en el territorio brasilero del PJe (Processo Judicial Eletrônico).

La Ley 13.105 de $2015^{25}$, adoptó el Código de Proceso Civil Brasileño (en adelante CPC) cuyos artículos 196, 231, 246, 270, 273 y 1050 modificaron la Ley 11.419 de 2006. Luego, el Consejo Nacional de Justicia de este país cumpliendo los mandatos del artículo 196 del Código de Proceso Civil, profiere la Resolución 234/2016 ${ }^{26}$, que establece el Diario de Justicia Electrónico Nacional (en adelante Dj-en), la Plataforma de Comunicaciones Procesales (domicilio electrónico) y la Plataforma de Edictos del Poder Judicial.

\section{Aspectos notorios del sistema de notificaciones judiciales electrónicas en Brasil}

De los aspectos más relevantes en el Sistema de Notificaciones Judiciales de Brasil, se reseñan, los siguientes:

\section{Tipos de notificación}

La Ley 11.419 de 2006, contempló inicialmente dos métodos de notificación electrónica. El primero, a través de los Diarios de Justicia Electrónica que cada tribunal crearía para el efecto; y el segundo, mediante la adhesión de las partes y sus abogados a un registro interno en el portal web de cada tribunal, de ahí que se acuñara bajo el término "auto-intimaçao".

Frente al primer método de notificación, el artículo 4 de la Ley 11.419 de 2006 dispone:

los tribunales podrán crear un Diario de Justicia Electrónico, disponible en el sitio de la red mundial de computadores, para la publicación de los actos judiciales y administrativos propios y de los órganos subordinados a ellos, como también para comunicaciones de contenido general ${ }^{27}$.

Constituido el DJE, este pasaría a ser el medio por antonomasia para las notificaciones judiciales, con las excepciones que la ley procesal contempla para los casos en los que se requiere la comparecencia personal del sujeto (Artículo 4 párr. 2, Ley 11.419/06).

Los actos que se publiquen a través del DJE se someten a un proceso de encriptación y se respaldan a través de un certificado electrónico proveniente de la entidad certificadora reconocida por la Infraestructura de Chaves Públicas Brasileira (ICP-Brasil, en adelante) (Artículo 4 párr. 1, Ley 11.419/06) ${ }^{28}$ que hará constar la autenticidad e integridad de esos documentos electrónicos para su plena validez jurídica.

La redacción prístina del párrafo 3 del artículo 4 de la Ley 11.419 de 2006 entendió que la fecha de la publicación electrónica, sería: "el primer día hábil siguiente al de la disponibilidad de la información en el DJE”, y en cuanto al cómputo de los plazos, el párrafo 4 de ese mismo artículo señala que empezarán a aplicar "a partir del primer día hábil siguiente al de la fecha de la publicación"; normas ratificadas por los párrafos 2 y 3 del artículo 224 del nuevo CPC. 
La difusión e implementación de los $\mathrm{DJE}^{29}$ por los tribunales determinó la emisión de la Resolución 234/2016 del Consejo Nacional de Justicia, por la cual se crea el Diario de Justicia Electrónico Nacional ${ }^{30}$, con el ánimo de sustituir a los DJE de los distintos órganos del Poder Judicial (Artículo 5).

El párrafo 2 del artículo 5 de la citada resolución indica que la notificación en el DJ-en, deberá señalar, so pena de nulidad: el tribunal, el órgano juzgador, el número de proceso, los nombres de las partes y sus apoderados, el número de inscripción en el Colegio de Abogados de Brasil o del bufete de abogados, según sea el caso. El artículo 6 continúa enumerando los actos que pueden publicarse en el DJ-en, y el artículo 7 reafirma el mandato de la Ley 11.419 de 2006, ya que este tipo de publicaciones deberán contar con el respectivo certificado digital con observancia a los requisitos trazados por la ICP-Brasil.

La segunda modalidad prevista en la Ley 11.419 de 2016 para surtir las notificaciones electrónicas consiste en un registro del interesado ante el correspondiente órgano judicial, según las políticas definidas para tal propósito, pero que siempre atenderá a la firma digital en cualquiera de las dos modalidades contempladas en los literales a y b del numeral III del artículo 2 de la Ley 11.419 de 06 . La firma digital cualificada requiere del respectivo certificado digital emitido por una autoridad certificadora acreditada por la ICP-Brasil, o el simple registro (usuario y contraseña) ante el propio poder judicial, que permita su autenticación (Articulo 2 párr. 1).

Cuando el usuario se adhiera a la modalidad de "auto-intimaçao", adquiere el compromiso activo de revisar periódicamente el portal web para conocer los actos que se le están notificado. De esa manera, se considerará realizada la notificación el día en que efectivamente el receptor hizo la consulta electrónica (art. 5 párr. $1^{\circ}$ Ley 11.419/06) a menos que su consulta ocurra en un día inhábil, caso en el cual se entenderá efectuada el primer día hábil siguiente (art. 5\$2 Ley 11.419/06).

En cualquier caso, cuando el usuario no cumple este compromiso, la Ley 11.419 de 2006entiende que "la consulta debe ser realizada dentro de los 10 días calendario siguientes a la fecha del envío de la comunicación" so pena de considerarse "surtida automáticamente la notificación en la fecha de expiración de ese plazo", lo que significa que los términos empezarán a aplicar a partir del día siguiente del vencimiento de ese plazo de 10 días, y que en caso de ser inhábil, se correrá para el siguiente día hábil (Artículo 5 párr. 3, Ley 11.419/06).

Por último, pero no menos importante, debe enfatizarse que el sistema también contempla el envío de correos electrónicos con carácter meramente informativo según el artículo 5párrafo 4 de la Ley 11.419/06 (pero que en ningún caso exonera al interesado de consultar el portal web), similar al "email de cortesía" previsto en Argentina, donde se le comunica la novedad en el sistema al interesado y se le invita a su consulta, recordándole los términos del Artículo 5 párr. 3 de la Ley 11.419/06.

\section{Sistemas de autenticación}

Según lo anterior, sin perjuicio de los reglamentos que cada órgano judicial establezca en desarrollo del artículo 18 de la Ley 11.419 de 2006, la norma consagra en los literales a y b del inciso III del artículo 1 el uso de la firma digital, en dos de sus variantes, como medio de autenticación. La primera, avalada por un certificado electrónico de una entidad de certificación digital adscrita a la ICP-Brasil; y la segunda, con el simple registro ante el tribunal.

\section{Responsables de los sistemas}

Respecto de los responsables del sistema, el texto originario de la Ley 11.419 de 2006 atribuía a cada órgano del poder judicial el desarrollo de los sistemas de gestión procesal y de las notificaciones electrónicas.

No obstante, la regla se modificó por el artículo 196 del CPC al asignar la competencia supletoria a los tribunales y, principalmente, al Consejo Nacional de Justicia para regular la práctica y comunicación oficial 
de los actos procesales por medio electrónico, velar por la compatibilidad de los sistemas y disciplinar la incorporación progresiva de nuevos avances tecnológicos en el poder judicial.

\section{Colombia}

\section{Aspectos normativos}

El primer antecedente normativo acerca de la incorporación de las tecnologías de la información en la Justicia colombiana, está contenido en la Ley 270 de $1996^{31}$ (Ley Estatutaria de Administración de Justicia, en adelante LEAJ), que ordenó al Consejo Superior de la Judicatura desarrollar estrategias que permitan el uso de los recursos tecnológicos en la "práctica de pruebas", "formación, conservación y reproducción de expedientes" y las "comunicaciones entre los juzgados". Para lograr este propósito, el precepto estableció que "los documentos emitidos por los citados medios, cualquiera que sea su soporte, gozarán de la validez y eficacia de un documento original siempre que quede garantizada su autenticidad, integridad y el cumplimiento de los requisitos exigidos por las leyes procesales" ${ }^{32}$.

En el año 1999, se profiere la Ley 527 para reglamentar el acceso y uso de los mensajes de datos, el comercio electrónico, las firmas digitales y las entidades de certificación. Esta normatividad brindó pautas adicionales en el entendimiento de la eficacia y validez de los documentos emitidos en soporte electrónico, consagró el principio de la "equivalencia funcional", y el mismo valor probatorio y eficacia jurídica al de los documentos escritos $^{33}$.

Por su parte, el Consejo Superior de la Judicatura mediante el Acuerdo 1591/02 desarrolló en forma limitada el mandato de la LEAJ, al adoptar el Sistema de Información de Gestión de Procesos y Manejo Documental (en adelante Justicia XXI), al limitarse a la consulta de procesos en línea ${ }^{34}$.

Después, el Consejo Superior de la Judicatura con el Acuerdo n. 3334 de 2006 consagra reglas importantes en torno a la utilización de los medios electrónicos para los actos de comunicación procesal dar al interior de la Rama Judicial. El acuerdo reafirma la importancia de la firma electrónica, el estampado cronológico, el certificado electrónico y la entidad de certificación, para la emisión de esta clase de actos ${ }^{35}$.

En al año 2011, la Ley 1437, por la cual se expide el Código de Procedimiento Administrativo y de lo Contencioso Administrativo (en adelante CPACA), reitera los mandatos de la LEAJ y ordena a la Sala Administrativa del Consejo Superior de la Judicatura adoptar las medidas necesarias para la implementación del "expediente judicial electrónico" en un plazo no mayor a 5 años ${ }^{36}$.

Similar redacción a la del CPACA se reproduce en el artículo 103 de la Ley 1564 de 2012 (Código General del Proceso, en adelante CGP), al encomendar a la Sala Administrativa del Consejo Superior de la Judicatura la labor de contar con los recursos técnicos para implementar el Plan de Justicia Digital y el numeral 5 del artículo 618 del CGP para adecuar la infraestructura en los despachos judiciales en un plazo de 6 meses a partir de su promulgación el 12 de Julio de $2012^{37}$.

Del mismo modo, la Ley 1563 de 2012 relativa al arbitraje nacional e internacional permite la utilización de las tecnologías en las actuaciones arbitrales y las notificaciones electrónicas.

Meses antes a la promulgación del Código General del Proceso, el Consejo Superior de la Judicatura aprobó el Plan Estratégico Tecnológico (en adelante PET) para la Rama Judicial Colombiana, mediante Acuerdo 9269 de $2012^{38}$. Dos de sus ejes centrales son la consolidación del expediente electrónico y la realización de las actuaciones judiciales a través de las tecnologías de la información, incluyendo las notificaciones judiciales ${ }^{39}$.

Ese plan estratégico se reafirma en el Acuerdo 9810 de 2013, mediante el cual la Sala Administrativa del Consejo Superior de la Judicatura, adopta el programa de acción para la implementación del "Código General del Proceso" y resalta que la adecuación de la infraestructura se cumpliría en dos fases; dejando para la segunda, 
el expediente electrónico mediante la actualización del Sistema de Gestión Judicial Justica XXI por el Sistema de Gestión Documental de la Rama Judicial (en adelante SGDRJ) ${ }^{40}$.

A pesar del amplio respaldo normativo, la implementación de los recursos tecnológicos en la Rama Judicial Colombiana ha sido muy lenta e ineficiente en la materialización de los acuerdos del Consejo Superior de la Judicatura. Recientes esfuerzos conjuntos del poder ejecutivo y el judicial, buscan poner en marcha el proyecto piloto de expediente electrónico judicial y ampliarlo a todos los procesos adelantados por la rama judicial, ${ }^{41}$ pero la adecuación aún continúa siendo lenta.

\section{Estado actual de las notificaciones electrónicas en el ámbito judicial}

A diferencia de otros países, Colombia no integra en un solo cuerpo normativo el régimen de notificaciones judiciales. Las normas aplicables varían conforme a la naturaleza de la controversia. Así, verbi gratia, para asuntos contencioso administrativos, se aplicará lo dispuesto en el CPACA y para asuntos civiles, comerciales, de familia y agrarios, el CGP.

Varias normas del CPACA tratan de las notificaciones electrónicas, a saber: el artículo 175 numeral 7 , que impone la obligación de incluir una dirección electrónica en la demanda, cuando el demandado sea una entidad pública o un particular que así la expresara en la demanda ${ }^{42}$; el artículo 197, que entiende que la notificación hecha al buzón electrónico de una entidad pública es personal; el artículo 199, que prevé la notificación personal del auto admisorio a la dirección electrónica de la entidad o un particular que deba estar inscrito en el registro mercantil o ejerza funciones públicas; el artículo 201 que habla de la fijación de estados electrónicos; y el artículo 205 que posibilita la notificación de otras providencias judiciales por medios electrónicos, siempre que así lo haya comunicado expresamente el interesado.

La notificación personal del auto admisorio de la demanda prevista en CPG difiere de la reglamentada en el CPACA, pues en el primero se remite la citación para que comparezca la persona a notificarse personalmente en el despacho judicial, y en el último se entiende que la comunicación enviada al buzón electrónico hace las veces de notificación personal (Artículo 291 núm. 3 CGP) ${ }^{43}$. Esta disposición, se aplica a las personas naturales que hayan suministrado al juez su dirección de correo electrónico, personas jurídicas de derecho privado y comerciantes inscritos en el registro mercantil, que hayan suministrado también una dirección electrónica para ese fin.

Al lado del artículo 291 del CGP, otras tres normas permiten la notificación por medios electrónicos. En efecto, el artículo 292, faculta el envío del aviso por medios electrónicos; el artículo 295 permite fijar estados electrónicos; y el parágrafo tercero del artículo 103, habilita el uso de "otros sistemas de envío, transmisión acceso y almacenamiento de mensajes de datos siempre que garanticen la autenticidad e integridad del intercambio o acceso de información" y "hayan sido reglamentados por el Consejo Superior de la Judicatura".

Tratándose de la notificación personal del auto admisorio de la demanda, en ambos regímenes se presume que el destinatario recibió la comunicación siempre que el iniciador, esto es, quién envía el mensaje, confirme acuse de recibo $^{44}$ (o para el caso del CPACA, se pueda constatar por otro medio) y el secretario deje constancia de ello en el expediente, adjuntando una impresión del mensaje de datos ${ }^{45}$.

Con respecto a la recepción del acuse de recibo, es preciso advertir que salvo que se haya acordado alguna forma específica para el recibo de comunicación entre el juzgado y el destinatario, puede acudirse a las opciones que contempla la Ley 527 de 1999, de cuyo artículo 20 se observa que el requisito puede cumplirse: "a) a través de toda comunicación del destinatario automatizada o no", o mediante "b) todo acto del destinatario que baste para indicar al iniciador que se ha recibido el mensaje de datos". De todas formas, en la práctica es más común que el envío de esta clase de notificaciones se haga a través de correos certificados que dan cuenta de la trazabilidad de la transacción, confirman el envío y la apertura del mensaje, como también, acusan recibo 
de la comunicación, mediante el envío de un certificado que incluye el estampado de tiempo ${ }^{46}$, o a través, del aplicativo CITANET.

Por último, debe anotarse que no todas las notificaciones que se surten por medios electrónicos requieren que el destinatario le acuse recibo al iniciador del mensaje, ello dependerá de la naturaleza del acto que se está notificando y del medio previsto por la ley para darle publicidad a ese acto. Por ejemplo, para las providencias que no requieren de notificación personal, estas se podrán hacer mediante la anotación en estados, y será suficiente la certificación del secretario en el caso de CPACA, o la simple inserción de los datos en el estado electrónico para CGP.

\section{CITANET}

Desde la adopción de Sistema Justicia XXI, se han intentado incorporar en la Rama Judicial otros programas de gestión, como CITANET. Este aplicativo busca apoyar el proceso de notificación de las actuaciones judiciales, mediante el envío de correos electrónicos, recepción de acuse de recibo, registro de actuaciones y en interoperabilidad con Justicia XXI.

El ingreso se da a través de Justicia XXI donde los funcionarios judiciales (secretario del juzgado) deben ingresar con sus credenciales y enviar las comunicaciones desde el correo electrónico oficial registrado, indicando el número de proceso y el destinatario ${ }^{47}$. Enviada la notificación, el sistema dejará el registro, reportando en la anotación si el correo fue enviado de manera exitosa al sujeto procesal, o si se produjo una falla en la entrega del mismo. A su vez, se emitirán los certificados correspondientes con estampados de tiempo.

Por último, se aclara que este módulo es unidireccional y no bidireccional, lo que imposibilita una comunicación activa por medios electrónicos entre los litigantes y despachos judiciales. En la actualidad, el responsable del mantenimiento de este aplicativo es la Unidad Informática de la Sala Administrativa del Consejo Superior de la Judicatura ${ }^{48}$.

\section{Costa Rica}

\section{Aspectos normativos}

Costa Rica es considerado uno de los pioneros en la región centroamericana respecto a la utilización de los recursos tecnológicos para surtir notificaciones en el Poder Judicial. La experiencia inicia con planes pilotos y se concreta con la denominada "Ley de Notificaciones Judiciales" (Ley 8.687 de 2008) que contiene una sección completa referida a las notificaciones por medio electrónico (Capitulo III, Sección I, Artículos 3946) ${ }^{49}$.

Asimismo, la Ley de Notificaciones Judiciales remite en lo no previsto por ella, al manual de procedimientos de las comunicaciones por medios electrónicos de las oficinas judiciales, que actualmente está contenido en la Circular 186-2014 de la Corte Suprema de Justicia y demás disposiciones concordantes como la Circular 184-2013 (reiterada por la Circular 47-2019) sobre "las buenas prácticas, para notificar, citar, localizar y presentar personas" y la "guía práctica de comunicaciones judiciales" (que se fundamenta en la Circular 184-2013) de reciente aprobación por el Consejo Superior del Poder Judicial, mediante Acta 25-19, Artículo LVI del 19 de marzo de $2019^{50}$.

Como resultado de esta normativa, Costa Rica mantiene en la actualidad dos expresiones de notificaciones judiciales electrónicas, una a través de lo que entiende por domicilio electrónico, y la otra por medio del sistema de gestión en línea. 


\section{Aspectos notorios de las notificaciones electrónicas en el Poder Judicial Costarricense}

\section{Domicilio electrónico}

El artículo 3 de la Ley de Notificaciones Judiciales dispone el primer uso de las notificaciones electrónicas y preceptúa: "las personas físicas y jurídicas podrán señalar al Poder Judicial, una dirección única de correo electrónico para recibir el emplazamiento y cualquier otra resolución, en cualquier asunto judicial en que deban intervenir. Esta fijación podrá ser modificada o revocada en cualquier tiempo, por la persona interesada" 51 .

Esta disposición debe interpretarse en consonancia con el artículo $39^{52}$, que le impone la carga al interesado de solicitar ante el Departamento de Tecnología de la Información del Poder Judicial, que acredite su cuenta de correo electrónica, mediante el suministro de los datos requeridos y dejándose constancia de lo actuado. Una vez realizado el registro ante la respectiva autoridad, el usuario puede constatar la información a través de la página $w^{5} b^{53}$, en la que, a través del formulario, el número de identificación, nombre, teléfono y dirección electrónica, hace el envío y recibe una confirmación de buen funcionamiento del correo electrónico. A partir de ese momento el correo electrónico quedará habilitado para el envío de las notificaciones y será responsabilidad del usuario revisarlo permanentemente.

\section{Otros medios electrónicos de notificación judicial}

La Ley de Notificaciones Judiciales también facultó a la Corte Suprema de Justicia para que "implemente otras modalidades de notificación, cuando los sistemas tecnológicos lo permitan" ${ }^{24}$ en su artículo 7 . En desarrollo de ese precepto, dentro del poder judicial costarricense se creó otro método de notificación judicial por vía virtual, consistente en el ingreso al "Servicio de Notificaciones en Línea 55 ", que requiere de un registro previo, donde el usuario se identificará y autenticará plenamente ante los despachos judiciales, para luego proporcionarle las respectivas credenciales de acceso al portal.

A diferencia de otros medios de notificación electrónica, la que ocurre a través del portal es de entera confianza y la responsabilidad de estar verificando activamente la página web recae sobre el litigante.

El sistema le proporciona al interesado también la posibilidad de ingresar por medio de certificado digital, que, para el efecto, deberá contar con unas especificaciones técnicas determinadas como la clase de navegador (que podrá ser Internet Explorer 8 o superior, Google Chrome u Opera), también con los controladores y el software de certificado digital y el lector de tarjetas inteligentes ${ }^{56}$.

\section{Responsables del sistema de notificaciones judiciales}

La Ley de Notificaciones Judiciales confía el sistema al Consejo Superior del Poder Judicial, a través del Departamento de Tecnología de la Información, y a la Corte Suprema de Justicia. En efecto, el citado artículo 7 de la Ley 8687/2008 le permite a la Corte Suprema de Justicia la creación de nuevos sistemas, y el artículo 18 del mismo cuerpo normativo faculta al Consejo Superior del Poder Judicial a reorganizar los mecanismos de notificación y a la creación de oficinas centrales de notificación $(\mathrm{OCN})^{57}$.

A su vez, los respectivos juzgados deberán designar a un servidor judicial que esté continuamente revisando el módulo de notificaciones (Artículo de 44, Ley 8687/2008,) y reportar las fallas en la infraestructura al Departamento de Tecnología de la Información del Poder Judicial (Artículo 45, Ley 8687/2008) ${ }^{58}$ 


\section{Consideración final}

Frente al momento en que se surte la notificación en el Sistema de Notificaciones Judiciales Electrónicas en Costa Rica, la norma ${ }^{59}$ dice que la persona quedará notificada el día "hábil" siguiente al de la transmisión y respecto al plazo para impugnarla, comenzará a correr a partir del día siguiente hábil al de la notificación.

Esta redacción ha causado confusión en las distintas jurisdicciones que componen la Rama Judicial Costarricense, por lo que la Corte Suprema de Justicia emitió un comunicado acordando que

si la última notificación se hace a cualquier hora de un jueves, incluidas las horas de la noche, la parte se tiene por notificada el día hábil siguiente, a saber, viernes, y el plazo para impugnar el respectivo pronunciamiento comienza a correr el lunes, o sea el día siguiente hábil a aquel en que se tuvo como efectuada la notificación. ${ }^{60}$

\section{Reseña a 'CITIUS'en Portugal}

En Portugal rige el aplicativo CITIUS que condensa la aplicación H@BILUS usada internamente por las secretarias de los tribunales judiciales portugueses desde el año $1999^{61}$, CITIUS-MP, que rige para los miembros del ministerio público y CITIUS- MJ, cuyo uso se atribuye a los Magistrados.

La aplicación CITIUS ${ }^{62}$ no solamente permite gestionar notificaciones electrónicas, sino que también posibilita la radicación de documentos y otros actos procesales, por lo que se aproxima más a lo que se conocer por una tramitación electrónica integrada.

La orden ministerial Portaria 114 de 2008 (cuya versión más reciente es la Portaria 280/2013, modificada parcialmente por la Portaria 267 de 2018 y a su turno por la Portaria 93/201963) disciplinó “varios aspectos en la tramitación electrónica de procesos judiciales” y marcó la pauta para órdenes subsiguientes y lograr la implementación progresiva de CITIUS. A ésta se suma otra, la Portaria 1538/2008 (actualizada por la Portaria $65-\mathrm{A} / 2010^{64}$ ) cuyo preámbulo reconoce la importancia de CITIUS y establece la adaptación progresiva al régimen de notificaciones electrónicas, reconocido en la Portaria 114 de 2008.

De la anterior normativa se extractan las siguientes características:

- Usuarios: La plataforma está dirigida a jueces, procuradores, oficiales de justicia, y abogados, los cuales deben realizar el registro ante la entidad responsable de la gestión de accesos. Por mencionar algunas de esas entidades, para el caso de los abogados, es necesario contar con un "certificado digital" que se obtiene con la inscripción en la Orden dos Avogados (Colegio de Abogados) y con ello el registro automático a CITIUS ${ }^{65}$, para los demás, el acceso se gestiona ante la entidad competente. En todo caso, la reglamentación exige que la autenticación de los usuarios se haga a través del uso de la firma digital avalada con su certificado electrónico correspondiente o a través de una tarjeta inteligente ${ }^{66}$.

- Notificaciones electrónicas: Del artículo 26 de la Portaria n. ${ }^{\circ} 280$ de 2013 se extraen dos supuestos en los que pueden ocurrir notificaciones electrónicas a través de CITIUS:

- Entre mandatarios: la notificación electrónica únicamente es posible si ambos abogados han consentido el envío de comunicaciones a través del portal o ambos han entregado algún documento a través de la plataforma.

- Entre juzgados y abogados: es necesario que el abogado haya expresado que desea las notificaciones por medio electrónico o que haya entregado algún documento a través de la plataforma CITIUS que entienda que ese es el medio que quiere usar para esos efectos.

- Seguridad en el envío de las notificaciones: En lo referente a la seguridad en el envío de las notificaciones por parte de los funcionarios judiciales, la normativa además de asegurar que el sistema certifique la identidad de quien ha sido notificado, el contenido de la misma, la fecha y hora en 
que se realizó la misma (Artículo 13), requiere que los actos que sean notificados por los juzgados, estén firmados electrónicamente y respaldados por un certificado electrónico emitido por el Sistema de Certificación Electrónica del Estado (esto para el caso de firma electrónica cualificada ) o por el Instituto de Gestión Financiera y Equipos de Justicia I. P. (para el caso de la firma electrónica avanzada), conforme a los artículos 19 y 20 de la Portaria 280 de 2013.

- Administración del Sistema: El sistema se encuentra a manos del Ministerio de Justicia y cuenta con la colaboración activa del Consejo Superior de la Judicatura, para lograr la mejora y el funcionamiento de la aplicación CITIUS.

\section{Breve comparación de los sistemas de notificación electrónica en los países iberoamericanos estudiados}

En la primera parte de este documento se hizo mención a los principales aspectos contemplados en las reglamentaciones de Argentina, Brasil, Colombia, Costa Rica y Portugal en torno a las notificaciones electrónicas en la esfera judicial.

En esta sección, se realiza una breve comparación de esas características para brindar una visión conjunta de los puntos más destacados expuestos previamente en cada uno de esos países.

\section{Marco jurídico}

En Argentina, la normativa que desarrolla las notificaciones electrónicas tiene fundamento legal singular. No obstante, su implementación se efectúa mediante las Acordadas, las cuales cuentan con un grado inferior dentro de la escala normativa.

En el caso brasilero, una ley específica reglamenta el proceso electrónico que contiene un capítulo concreto para las "notificaciones" por medios electrónicos. La característica más peculiar de la normatividad brasilera radica en establecer un solo sistema de tramitación electrónica que incorpore dos plataformas interoperables, una para las notificaciones personales, y otra para los edictos del Poder Judicial.

En Colombia, la situación es análoga a la de Argentina. Se cuentan con varias normas que sustentan la utilización de los recursos electrónicos en la rama judicial, pero su implementación se hace mediante "acuerdos" del Consejo Superior de la Judicatura, cuya naturaleza, es la de actos administrativos de inferior jerarquía normativa.

Por su parte, Costa Rica tiene una ley propia de notificaciones judiciales que dedica un capítulo exclusivo a las "notificaciones por medios electrónicos" y en lo no previsto remite a las circulares de la Corte Suprema de Justicia.

A diferencia de los demás países, donde el marco normativo cuenta con un fundamento legislativo, en Portugal está compuesto en su totalidad por "portarias", es decir, por actos administrativos provenientes del Ministerio de Justicia que han demostrado eficacia en reglamentar el sistema CITIUS.

En síntesis, con excepción de Portugal, en Argentina, Colombia, Costa Rica y Brasil existe un respaldo legislativo expreso, pero su implementación se ha dado a través de actos administrativos que buscan materializar esos mandatos, fijando las pautas esenciales para la operatividad de los sistemas, en particular a propósito de los tipos de aplicativos, la clase de usuarios, las providencias susceptibles de notificación por estos medios y el cómputo de los plazos, entre otros aspectos de gran importancia para el correcto funcionamiento de los diversos sistemas. 


\section{Herramienta Informática}

Con herramientas informáticas nos referimos al conjunto de sistemas, aplicativos, plataformas o programas que permiten la sistematización de la información y ayudan a simplificar el desarrollo de una actividad. Para el caso de las notificaciones por medios electrónicos, la herramienta podría concretarse en un aplicativo, plataforma web o simplemente consistir en un servicio de intercambio de comunicaciones, como el correo electrónico.

En la mayoría de los países iberoamericanos seleccionados se observa una tendencia a la utilización de plataformas web para gestionar las notificaciones electrónicas, tal es el caso de Argentina, Brasil y Costa Rica. En Argentina, la herramienta informática del poder central, es una plataforma web denominada "SNE" y que está a cargo de la dirección de sistemas de la Corte Suprema de Justicia de la Nación. En Brasil, existen varias plataformas web, a manos de los distintos tribunales que componen el sistema judicial brasilero y del Consejo Nacional de Justicia.

El Servicio de Notificaciones en Línea costarricense es una verdadera plataforma en línea, administrada por el Departamento de Tecnología de la Información del Consejo Superior del Poder Judicial y la Corte Suprema de Justicia.

En otras latitudes como Portugal, el avance ha sido aún mayor estableciéndose un aplicativo bidireccional (CITIUS), a cargo del Ministerio de Justicia y el Consejo Superior de la Judicatura.

De una forma más precaria en el manejo de los recursos tecnológicos, se encuentra Colombia con el aplicativo CITANET, cuya administración recae en la Unidad Informática de la Sala Administrativa del Consejo Superior de la Judicatura. Como se indicó anteriormente, este aplicativo es una herramienta unidireccional que en realidad no permite interacción alguna entre el juzgado y los sujetos procesales, por lo que se implementa en mayor medida el registro de correos personales para notificar las distintas providencias judiciales.

En definitiva, para un resumen de las herramientas y responsables ver la tabla 1.

TABLA 1.

\section{Herramienta Informática}

\begin{tabular}{lll}
\hline País & Herramienta & Responsable del Sistema \\
\hline Argentina & Portal web & $\begin{array}{l}\text { Corte Suprema de Justicia de } \\
\text { la Nación }\end{array}$ \\
\hline Colombia & Aplicativo/Correo electrónico & $\begin{array}{l}\text { Consejo Superior de la } \\
\text { Judicatura }\end{array}$ \\
\hline Brasil & Portal web & $\begin{array}{l}\text { Consejo Nacional de Justicia/ } \\
\text { Tribunales }\end{array}$ \\
\hline Costa Rica & Portal web & $\begin{array}{l}\text { Departamento de Tecnología } \\
\text { de la Información del Consejo } \\
\text { Superior del Poder Judicial y } \\
\text { la Corte Suprema de Justicia }\end{array}$ \\
\hline Portugal & Aplicativo & $\begin{array}{l}\text { Ministerio de Justicia/Consejo } \\
\text { Superior de la Judicatura }\end{array}$ \\
\hline
\end{tabular}

Fuente: elaboración propia

\section{Usuarios, registro e ingreso a los distintos sistemas}

Una característica común a los países que tienen consolidado un sistema de notificaciones electrónicas en el ámbito judicial distinto al simple envío de correos electrónicos, es la presencia de dos clases de usuarios; por un lado, los externos, y por el otro, los internos.

Por ejemplo, en Argentina, el anexo I de la Acordada 31/11 reconoce que los usuarios externos del SNE son: "los abogados, funcionarios del Ministerio Público y toda persona que litigue por derecho propio" y dentro de los internos se encuentran "los funcionarios o empleados del tribunal".

Como se indicó previamente, para poder hacer uso del SNE, los usuarios externos deben contar con un registro previo, que comprende una fase virtual y otra presencial, la cual ocurre posteriormente ante un 
funcionario del poder judicial. Realizado el registro presencial, el ingreso al sistema para estos usuarios, se efectuará en línea, proporcionando las credenciales que le fueron suministradas una vez finalizado el registro. Para los usuarios internos del sistema, el registro ocurre dentro del despacho judicial al que pertenecen y su ingreso también se hace mediante el uso de códigos de acceso, a través del portal web habilitado para el efecto.

En igual sentido, Costa Rica a través de su "servicio de notificaciones en línea" contempla la existencia de unos usuarios externos, que serían los apoderados judiciales, los cuales deben registrarse previamente ante las autoridades judiciales competentes para poder hacer uso del sistema.

En cuanto a los usuarios internos, el sistema se reserva a los servidores judiciales, y en ellos recae la obligación de verificar la operatividad y fallas en el sistema. El acceso de los usuarios externos al portal se hace mediante el sistema de usuario y contraseña, sin perjuicio de que, si lo desean, lo puedan hacer a través de un "certificado digital" que brinda mayores controles de seguridad. En el caso de los usuarios internos, su ingreso se hace mediante las credenciales que le son proporcionadas como funcionarios del poder judicial.

Portugal, el más avanzado de estos países, cuenta igualmente con usuarios externos e internos. La característica principal de los usuarios externos es que su registro se hace ante una entidad específica y no ante un funcionario del poder judicial, como sí ocurre en otros países. Para ingresar a la plataforma todos los usuarios (internos y externos) deben contar con el respaldo obligatorio de la firma digital, avalados con su certificado electrónico correspondiente o mediante el uso de la tarjeta inteligente. Esta característica es, precisamente, la que hace que el sistema que rige en Portugal se destaque y diferencie de otros, como los que imperan en Argentina y Colombia, donde el ingreso o la autenticación de los usuarios a los sistemas no tiene un control mayor de seguridad, sino que se limita al simple uso del usuario y contraseña.

En Colombia, el aplicativo CITANET es unidireccional, por lo que. en esencia, el uso de la plataforma se limita a los funcionarios judiciales que tendrían la connotación de ser usuarios internos y cuyo ingreso se daría a través del sistema Justicia XXI mediante el diligenciamiento de las credenciales correspondientes. En lo tocante a los usuarios externos, la plataforma aún no los incorpora, por lo que basta con el simple registro del correo personal para habilitarles la notificación de ciertas providencias judiciales.

Finalmente, se recuerda que en Brasil coexisten varios sistemas de gestión procesal y cada uno cuenta con sus reglas específicas en torno a las "notificaciones judiciales electrónicas", pero se debe hacer memoria que todos deben regirse por los parámetros comunes establecidos en la Ley 11.419 de 2006. Por lo anterior, cada tribunal a través de su portal web cuenta con usuarios externos e internos. Los usuarios externos que serían principalmente los apoderados judiciales, deben hacer su registro previo ante los respectivos órganos judiciales. El acceso de los usuarios externos al sistema, puede darse por medio de la firma digital cualificada o por medio de un simple registro (usuario y contraseña) ante el propio poder judicial. Para el caso de los usuarios internos, el sistema prevé el usuario y contraseña como medio de autenticación.

En síntesis, las clases de usuarios, el registro y acceso, se esquematiza como se indica en la tabla 2:

TABLA 2.

Clases de usuarios

\begin{tabular}{llll}
\hline País & Clases de usuarios & $\begin{array}{l}\text { Registro } \\
\text { previo }\end{array}$ & $\begin{array}{l}\text { Acceso/ } \\
\text { Autenticación }\end{array}$ \\
\hline Argentina & Internos/Externos & Sí & Vía web \\
\hline Colombia & Solo internos & Solo internos & Vía web \\
\hline Brasil & Internos/Externos & Sí & $\begin{array}{l}\text { Vía web/Firma } \\
\text { digital (opcional) }\end{array}$ \\
\hline Costa Rica & Internos/Externos & Sí & $\begin{array}{l}\text { Vía web/Firma } \\
\text { digital (opcional) }\end{array}$ \\
\hline Portugal & Internos/Externos & Sí & $\begin{array}{l}\text { Firma digital } \\
\text { (obligatorio) }\end{array}$ \\
\hline
\end{tabular}

Fuente: elaboración propia 


\section{Providencias que son susceptibles de notificarse por medios electrónicos, momento de la notificación y cómputo de los plazos}

El SNE argentino inicialmente comprendió la notificación de los escritos que negaban los recursos de quejas de los tribunales del poder judicial de la nación. Hoy en día, el sistema no solo se usa para los recursos de queja, se extiende también para todas las "providencias, resoluciones y sentencias que deban practicarse personalmente o por cédula" ${ }^{37}$. La notificación en estos casos, ocurrirá en el domicilio electrónico del sujeto procesal y será de manera automática, es decir, desde el mismo momento en que la providencia esté lista para su consulta, sin que sea necesario verificar si el usuario efectivamente ingresó o no al sistema. En el cómputo, deberán descontarse los días inhábiles. A su vez, se recuerda que el sistema contempla el "email de cortesía" sin que ello constituya notificación, pues bien señala la normativa que se trata de una alerta en el sistema que debe ser atendida por el usuario y no suple la verdadera notificación.

Como se expresó anteriormente, los medios de notificación electrónica en Brasil, se materializan a través de los Diarios de Justicia Electrónica y la auto-intimaçao. En el primer caso, enfatiza que la Resolución 234/2016 trajo consigo la creación de un Diario de Justicia Electrónico Nacional (DJ-en), que pretende sustituir a los "Diarios de Justicia Electrónica" al interior de cada tribunal. En el DJ-en se pueden notificar todas aquellas actuaciones que no requieran la comparecencia personal del sujeto, por ejemplo, autos interlocutorios, sentencias, citaciones destinadas a los apoderados judiciales, entre otros actos señalados en el Artículo 6 de la Resolución 234/2016.

En cuanto al momento de la notificación, la ley entendió que se surte en el primer día hábil en el que la información esté disponible en el DJ-en, y en lo que tiene que ver con el cómputo del plazo, se entiende que correrá a partir del primer día hábil siguiente al de la fecha de publicación.

En lo que respecta a la auto-intimaçao, las reglas que trae consigo la legislación brasilera son claras: el mecanismo es supletorio y requiere la adherencia del interesado. Se encuentra esencialmente previsto para todo tipo de notificaciones, incluyendo las personales. La notificación se entiende surtida el día en que, efectivamente, el receptor la consulte en el portal web, y si se trata de un día inhábil, se moverá al siguiente día hábil. Esta regla también aplica para el plazo, que se contará a partir del siguiente día hábil al que se realizó la consulta. De todas formas, si el receptor no efectúa la consulta dentro de los 10 días calendario siguientes a la fecha del envío de la comunicación, se entiende automáticamente surtida la notificación al finalizar esos 10 días calendario y los plazos para pronunciarse frente a ese acto comenzarán a contarse a partir del siguiente día hábil del vencimiento de ese término. En este último caso, la notificación es inmediata y se origina luego de que se le venza la oportunidad al receptor de consultarla voluntariamente.

En Colombia, las disposiciones procesales que permiten la utilización de los medios electrónicos para notificar actuaciones judiciales se encuentran dispersas en dos cuerpos normativos (CGP y CPACA). En línea de principio, ambas normatividades prevén la posibilidad de fijar estados electrónicos, enviar avisos electrónicos y surtir la notificación personal de ciertas providencias, como la del auto que admite la demanda, por medios electrónicos, por lo que este medio se utiliza ampliamente para varias clases de providencias judiciales (autos y sentencias).

Sobre este punto vale la pena destacar, que, si se trata de la notificación de un auto o sentencia que no deba realizarse por otro medio, ambas normativas señalan que ésta podrá cumplirse a través de la fijación de un estado electrónico. Para el efecto, se fijará el estado al día siguiente de la fecha de la providencia al comenzar la primera hora hábil del respectivo día y se desfijará al finalizar la última hora hábil del mismo. Vencido ese plazo, empezarán a correr los respetivos términos para que las partes puedan pronunciarse frente al acto que se les está notificando.

Si se trata de un aviso, se enviará a la dirección electrónica proporcionada por el destinatario. En este caso, para que se entienda surtida la notificación, el destinatario deberá acusar recibo del envío de la comunicación 
y el secretario deberá dejar constancia de ello en el expediente. Cumplido lo anterior, a partir del día siguiente empezarán a correr los términos pertinentes.

Frente a la notificación personal, vale la pena detenerse en la de auto admisorio, recordando lo expuesto anteriormente acerca de la diferencia entre el régimen previsto en el CGP y el CPACA, es decir, que mientras en el primero se envía la citación para que comparezca a notificarse, en el segundo la citación hace las veces de notificación. En uno u otro caso, siempre será indispensable que el destinatario acuse recibo y el secretario deje constancia en el expediente. Cumplida la notificación, empezarán a correr los términos legales para que las partes puedan ejercer las conductas que en derecho estimen procedentes.

Costa Rica, con la ley de notificaciones judiciales hace posible recibir el emplazamiento o la notificación de cualquier resolución judicial sin distinción de la clase de asunto, en el domicilio electrónico de la persona interesada o a través del Servicio de Notificaciones en Línea. En torno al momento en que se entiende surtida la notificación, la normatividad entiende que será al siguiente día "hábil" y el plazo para impugnarla, comenzará a correr a partir del siguiente día hábil al que se surtió la notificación.

Por último, en Portugal, para que las notificaciones se surtan a través de la plataforma CITIUS es necesaria la manifestación expresa de las partes de adherirse al sistema. Una vez se cuente con ella, el sistema sirve para notificar cualquier providencia judicial sin restricción alguna. El sistema también permite el intercambio de comunicaciones entre los mandatarios procesales. Las notificaciones se producen de manera automática, el sistema le envía una alerta de novedad a los apoderados judiciales para que consulten el acto que se está notificando. Verificada la novedad, empezarán a correr los términos procesales pertinentes que varían según el acto notificado. Lo expuesto se condensa en la tabla 3

TABLA 3.

Tipos de Notificaciones

\begin{tabular}{|c|c|c|c|}
\hline País & $\begin{array}{l}\text { Momento de la } \\
\text { notificación }\end{array}$ & $\begin{array}{l}\text { Providencias susceptibles de } \\
\text { notificación electrónica }\end{array}$ & Plazos \\
\hline Argentina & Directa/Automática & $\begin{array}{l}\text { Providencias, resoluciones y } \\
\text { sentencias que puedan ser } \\
\text { notificadas personalmente o por } \\
\text { cédula. }\end{array}$ & $\begin{array}{l}\text { Inmediato } \\
\text { (descontando días inhábiles) }\end{array}$ \\
\hline Brasil & $\begin{array}{l}\text { Puede ser o no } \\
\text { directa. }\end{array}$ & $\begin{array}{l}\text { Todas las actuaciones que no } \\
\text { requieran comparecencia personal, } \\
\text { para el caso de los DJ-en. En el } \\
\text { caso de la auto-intimaçao, } \\
\text { cualquier acto. }\end{array}$ & $\begin{array}{l}\text { Desde el momento de la } \\
\text { consulta o del vencimiento del } \\
\text { plazo de gracia o al siguiente } \\
\text { día hábil de la publicación de } \\
\text { la información en el diario } \\
\text { electrónico. }\end{array}$ \\
\hline Colombia & $\begin{array}{l}\text { No cs dirccta, } \\
\text { requiere acuse de } \\
\text { recibo, salvo el } \\
\text { estado electrónico. }\end{array}$ & $\begin{array}{l}\text { Autos y sentencias. Por regla } \\
\text { general, se excluyen las } \\
\text { providencias que requieren } \\
\text { notificación personal (con } \\
\text { excepción de algunas). }\end{array}$ & $\begin{array}{l}\text { El cómputo varía conforme al } \\
\text { medio de notificación. } \\
\text { (Estado, Aviso o Personal) }\end{array}$ \\
\hline $\begin{array}{l}\text { Costa } \\
\text { Rica }\end{array}$ & Directa & $\begin{array}{l}\text { Emplazamientos o cualquier tipo } \\
\text { de resolución judicial. }\end{array}$ & $\begin{array}{l}\text { A partir del siguiente día hábil } \\
\text { al que se surtió la notificación. }\end{array}$ \\
\hline Portugal & $\begin{array}{l}\text { Recepción/ } \\
\text { Aceptación }\end{array}$ & Cualquier providencia- & $\begin{array}{l}\text { Varía conforme al acto a } \\
\text { notificar. }\end{array}$ \\
\hline
\end{tabular}

Fuente: elaboración propia

\section{Seguridad en el envío de las notificaciones electrónicas}

Otras de las características que merece la pena comentar así sea sucintamente, es la relativa a los esquemas de seguridad que implementan estos países para el envío de notificaciones electrónicas. Sin estos esquemas, fácilmente podría el sujeto alegar que la comunicación nunca llegó, dejando a su discreción la notificación de la providencia y con ello la manipulación de los términos para atenderla.

En el caso argentino, los actos que se notifican a través del SNE deben estar firmados digitalmente por la respetiva autoridad judicial y contar con el respaldo del certificado electrónico. Una vez que la providencia a notificar se encuentre en el sistema, el usuario podrá ingresar con sus credenciales y deberá contar con el respectivo certificado de firma digital para poder consultar en su "casillero electrónico" las notificaciones que se le vayan realizando de los distintos trámites que tenga a su cargo ante los juzgados. 
La normatividad brasilera se ocupó de otorgarle mayores controles de seguridad a las notificaciones que tienen soporte electrónico. Así, no basta únicamente con el simple proceso de encriptación para las notificaciones que se publiquen en el DJ-en, sino que requieren igualmente el respaldo de un certificado electrónico otorgado por la ICP-Brasil. Para la segunda modalidad prevista en Brasil, cada tribunal es autónomo de fijar los requisitos que rigen la seguridad en el envío de la comunicación. Sin embargo, como pauta común, se señala el uso de la firma digital en cualquiera de las variantes que consagra la ley para que el interesado ingrese al portal y consulte la respectiva notificación.

En Colombia, el aplicativo CITANET simplifica el proceso y otorga mayor seguridad en el envío de la comunicación, porque el mismo sistema monitorea el envío de la notificación y genera el reporte de su entrega, emitiendo los respectivos certificados con etiquetas de tiempo. Sin embargo, el aplicativo no se utiliza en todos los casos, por lo que debe acudirse a las normas procesales específicas, cuya redacción parece ser ineficiente, toda vez que requieren que el receptor "acuse recibo" de la comunicación, y en la mayoría de las veces el destinatario no lo hace, con lo que se ve frustrada la notificación y los plazos para atenderla. Por lo anterior, es común que en la práctica se haga uso de correos certificados avalados por una entidad certificadora para evitar que la notificación quede sujeta a la manipulación de las partes, con lo cual se evidencia la necesidad de complementar o reformar el contenido de esas normas procesales.

Por su parte, en Costa Rica, las actuaciones que se notifican por medios electrónicos deben estar firmados digitalmente y acompañados de un código de barras que permiten verificar su autenticidad. En caso de que la notificación se surta a través del sistema de gestión en línea, el usuario deberá autenticarse y el mismo sistema generará los respectivos certificados de apertura de la comunicación.

Finalmente, en el sistema CITIUS de Portugal las comunicaciones que se notifiquen a través del aplicativo cuentan con un alto grado de seguridad, ya que además de identificar el sujeto al que se le va a notificar el acto, deben estar firmadas electrónicamente y contar con el respectivo certificado electrónico emitido por la autoridad competente. La tabla 4 muestra una síntesis respecto a la seguridad de cada sistema.

TABLA 4.

Seguridad

\begin{tabular}{ll}
\hline País & Esquema de Seguridad \\
\hline Argentina & Certificado electrónico + Firma digital. \\
\hline Colombia & Correo electrónico certificado. \\
\hline Brasil & $\begin{array}{l}\text { Encriptación + Certificado electrónico + Firma } \\
\text { digital }\end{array}$ \\
\hline Costa Rica & Firma digital \\
\hline Portugal & Certificado electrónico + Firma electrónica \\
\hline
\end{tabular}

Fuente: elaboración propia

\section{Domicilio electrónico}

El domicilio electrónico reviste especial importancia en Argentina y Costa Rica, no siendo igual para Brasil, Colombia y Portugal.

En el caso argentino, el domicilio electrónico es un requisito indispensable para poder darse de alta en el sistema y que viene a ocupar el código de usuario del interesado.

Por su parte, en Costa Rica, el domicilio electrónico, es otra de formas para surtir notificaciones electrónicas y se reduce simplemente al registro de una dirección de correo electrónico proporcionada por el interesado.

En ambos casos, aunque el domicilio electrónico corresponde a distintos elementos, se traduce en un requisito necesario para poder recibir notificaciones por parte de los tribunales en formato electrónico y sin el cual se frustraría la notificación. 


\section{Conclusiones}

Este artículo presentó sucintamente la normatividad vigente y el estado actual en cinco países iberoamericanos en torno a la implementación de los recursos tecnológicos en la notificación de providencias judiciales.

La mayoría de los países han incorporado los recursos tecnológicos en el poder judicial. Todos los países iberoamericanos estudiados tienen una reglamentación distinta en cuanto a los requisitos exigidos para la seguridad de las comunicaciones. Unos utilizan la firma digital cualificada o avanzada, y otros se inclinan por el simple acceso rápido a través de un portal web.

En sentido análogo, puede decirse:

- En el caso argentino, la experiencia se ha dado por etapas, lo que ha permitido establecerse un sistema de notificaciones electrónicas a través del ingreso a un portal web a nivel nacional, con previo registro del interesado y que genera una notificación de forma automática. Se contempla el "email de cortesía" que en ningún caso se entiende que sea una notificación.

- En la experiencia brasilera, la normativa autoriza la creación de varios sistemas de gestión procesal al interior de los tribunales de justicia, lo que ha llevado a que cada tribunal tenga su propio sitio web, que según sea el caso podrá adoptar la firma digital o el simple registro.

- Para el caso colombiano, las notificaciones judiciales se surten a través de correo electrónico y se hace necesario el acuso de recibo de la comunicación cuando la ley exige que la providencia que se notifica sea personal. En los demás casos, la notificación se surte por otros medios electrónicos donde solo bastará la respectiva certificación. Por otra parte, aún no posee una plataforma bidireccional que permita la comunicación activa entre los usuarios y el despacho judicial. La aplicación actual es para uso interno de los despachos judiciales y se notifica a las cuentas personales de los sujetos procesales.

- Por su parte, Costa Rica es uno de los países que ha sabido implementar la tecnología para gestionar notificaciones en soporte informático. En la actualidad se pueden recibir notificaciones al correo electrónico del interesado o a través de un portal web que requiere de registro previo. Una vez se cuente con él, hay plena garantía y seguridad del acto que se está notificando.

- Dentro de los sistemas más avanzados se halla Portugal, el cual dispone de toda una plataforma que permite gestionar las notificaciones con un alto nivel de seguridad (firma digital) garantizando la trazabilidad de la operación.

Debido a estas características más relevantes como usuarios, providencias susceptibles de notificación, celeridad y seguridad en los distintos ordenamientos jurídicos, el uso de las tecnologías, en particular en el ámbito de las notificaciones judiciales, ha contribuido a la eficiencia del sistema al permitir la reducción de costos, tiempos, desplazamientos, agilizar las actuaciones, dar a conocer las providencias en forma ágil, y posibilitar el ejercicio oportuno derecho de contradicción y defensa.

En el caso de la Argentina, el uso de la tecnología ha sido de gran utilidad porque ha permitido reemplazar los métodos tradicionales de notificación judicial por los medios electrónicos. Con su uso se ha mejorado el servicio de Justicia al simplificar los trámites e incentivando la cultura de "cero papel”. También, ha permitido un mayor número de notificaciones en promedio, favoreciendo a los operadores judiciales y a los ciudadanos, que al conocer desde cualquier lugar los actos que se le notifican, puede actuar rápidamente.

En Costa Rica, los recursos tecnológicos son de gran ayuda para la administración de justicia. En primer lugar, han agilizado la tramitación de los procesos judiciales al reducirlos tiempos de consulta y evitar desplazamientos a los despachos judiciales. En segundo lugar, han facilitado el acceso de los usuarios a la administración de justicia; y, en tercer lugar, han permitido que las decisiones judiciales sean conocidas por los destinatarios de una manera expedita y segura. 
Por su parte, en Colombia, pese a existir un marco normativo amplio, la implementación de las nuevas tecnologías al proceso es aún precaria. Existen varios intentos por consolidar un sistema de gestión electrónica integral, pero se han presentado muchos inconvenientes en la práctica. en relación con las notificaciones electrónicas, se evidencia un cambio positivo, ya que a través del envío de correos certificados se ha incentivado el uso de los medios electrónicos para notificar las actuaciones judiciales y ha generado mayor aceptación en el ámbito judicial.

Igualmente, Brasil y Portugal reportan beneficios en la implementación de la tecnología al interior del poder judicial, ya que no solo cuentan con sistemas que permiten gestionar electrónicamente las actuaciones judiciales, sino que también imponen una mayor velocidad al proceso, reducen significativamente los costos, preservan el medio ambiente y aumentan la publicidad de los actos.

En definitiva, el uso de las notificaciones electrónicas y su implementación varia conforme la infraestructura técnica de cada país y la reglamentación para su difusión. En algunos más avanzada, mientras que en otros se han dados pasos de particular importancia para superar obstáculos y lograr el mejoramiento paulatino de la tecnología, pese a la carencia de los suficientes recursos técnicos, con el fin de gestionar de manera virtual sus procesos.

\section{Referencias}

Acordada n. ${ }^{\circ}$ 11/2014 [Corte Suprema de Justicia de la Nación]. Sistema de Notificaciones Electrónicas, Defensores y Fiscales. 7 de mayo de 2014. B.O. 32.878 (Argentina).

Acordada n. ${ }^{\circ}$ 29/2012 [Corte Suprema de Justicia de la Nación]. Notificaciones por Medios Electrónicos. Obligatoriedad. 25 de febrero de 2013. B. O. 32.587 (Argentina).

Acordada n. ${ }^{\circ}$ 3/2012 [Corte Suprema de Justicia de la Nación]. Sistema de Notificaciones por Medios ElectrónicosAplicación. 4 de abril de 2012. B. O. 32.371 (Argentina).

Acordada n. ${ }^{\circ}$ 3/2015 [Corte Suprema de Justicia de la Nación]. Aprobar pautas ordenatorias para garantizar el adecuado y actualizado uso de los nuevos sistemas informáticos que se encuentran implementados, así como el correcto tratamiento de las particulares características que involucran a las partes y otros intervinientes en el proceso. 25 de febrero de 2015. B. O. 33.077 (Argentina).

Acordada n. ${ }^{\circ}$ 31/2011 [Corte Suprema de Justicia de la Nación]. Sistema de Notificaciones por Medios ElectrónicosAplicación. 4 de abril de 2012. B. O. 32.371 (Argentina).

Acordada n. ${ }^{\circ}$ 35/2013 [Corte Suprema de Justicia de la Nación]. Establecer que el Sistema de Notificaciones por Medios Electrónicos Reglamentado por la Acordada 31/2011 es de aplicación obligatoria. 4 de octubre de 2013. B. O. 32.737 (Argentina).

Acordada n. $36 / 2013$ [Corte Suprema De Justicia De La Nación]. Establecer que el Sistema de Notificaciones por Medios Electrónicos Reglamentado por Acorada 31/2011 será de aplicación con relación a las notificaciones que deben efectuarse en las causas radicadas ante la jurisdicción prevista en el artículo 117 de la Constitución nacional, con arreglo a lo dispuesto en la Acordada 51/73. 4 de octubre de 2013. B. O. 32.737 (Argentina).

Acordada n. ${ }^{\circ}$ 38/2013 [Corte Suprema de Justicia de la Nación]. Sistema de Notificaciones por Medios Electrónicos. Obligatoriedad. Apruébese el plan de difusión y capacitación. 17 de octubre de 2013. B. O. 32.745 (Argentina).

Acta de Consejo Superior n. ${ }^{\circ}$ 025/ 2019 [Consejo Superior del Poder Judicial]. DOCUMENTO n. ${ }^{\circ}$ 2748-19 "por medio de la cual se adjunta el documento denominado: 'Guía Práctica de Comunicaciones Judiciales', para que la misma sea aprobado por los integrantes del Consejo Superior". https://nexuspj.poder-judicial.go.cr/docume nt/act-1-0003-3713-48/acta

Acuerdo n. ${ }^{\circ}$ 1591/02 [Consejo Superior de la Judicatura] por el cual se establece el sistema de información de gestión de procesos y manejo documental (Justicia XX). 24 de octubre de 2002. (Colombia) 
Acuerdo n. ${ }^{\circ} 3334 / 2006$ [Consejo Superior de la Judicatura]. Por el cual se reglamenta la utilización de medios electrónicos e informáticos en el cumplimiento de las funciones de administración de justicia. 2 de marzo de 2006 (Colombia).

Acuerdo n..$^{\circ}$ 9269/2012 [Consejo Superior de la Judicatura]. Por el que se expide el Plan Estratégico Tecnológico de la Rama Judicial. 27 de febrero de 2012 (Colombia).

Acuerdo n. ${ }^{\circ}$ 9810/2013 [Consejo Superior de la Judicatura]. Por el cual se adopta el plan de acción para la implementación del Código General del Proceso. 25 de abril de 2013 (Colombia).

Certicámara, Correo electrónico certificado - Certimail. https://web.certicamara.com/productos_y_servicios/Plataf ormas_Cero_Papel/42-Correo_Electrónico_Certificado_-_Certimail

Circular n. ${ }^{\circ}$ 42-2011 [Corte Suprema de Justicia]. Aplicación del artículo 38 de la Ley de Notificaciones Judiciales (n. - 8687). http://www.pgrweb.go.cr/scij/Busqueda/Normativa/Normas/nrm_texto_completo.aspx?param1 =N RTC\&nValor $1=1 \&$ nValor2=70140\&nValor3=84536\&strTipM=TC

Código de Procedimiento Administrativo y de lo Contencioso Administrativo [CPACA]. Ley 1437/2011.18 de enero de 2011 (Colombia).

Código General del Proceso [CGP]. Ley 1564 de 2012. 12 de julio de 2012 (Colombia).

Código Procesal Civil y Comercial [CPCCN]. Ley 17.454 de 1981.Art. 152 (Argentina).

Código Processo Civil [CPC]. Lei 13.105 de 2015 (Brasil).

Davinsson Nunjar Flores, Sistema Costarricense de Información Jurídica.

Demócrito Reinaldo Filho, Comunicação eletrônica de atos processuais na Lei no 11.419/06 (2019). https://jus.com .br/artigos/9750/comunicacao-eletronica-de-atos-processuais-na-lei-n-11-419-06

Diario de Justicia Electrónico, Conselho Nacional de Justiça (CNJ) (s. f.). http://www.cnj.jus.br/dje/djeletronico?vis aoId=tjdf.djeletronico.comum.internet.apresentacao.VisaoDiarioEletronicoInternetPorData

Edgar Valles, Prática Processual Civil (10 ed., Almedina, 2019)

Germán Gómez Rojas, Alianza por la transformación de la justicia con Expediente Electrónico Judicial. Noticias Corte Suprema de Justicia (2019). http://www.cortesuprema.gov.co/corte/index.php/2018/12/12/alianza-por-la-tra nsformacion-de-la-justicia-con-expediente-electronico-judicial/

Herney de Jésus Ortiz Montacada, Notificaciones, Traslados y Avisos, en El Juicio por Audiencias en la Jurisdicción de lo Contencioso Administrativo: Guías Procesales Casos Típicos (María Cristina Gómez Isaza ed., 2012). http://www.tribunaladministrativoantioquia.info/wp-content/uploads/2014/11/El-Juicio-por-audien cias-CPACA-PRIMERA-PARTE.pdf

Institui a Infra-Estrutura de Chaves Públicas Brasileira - ICP-Brasil, transforma o Instituto Nacional de Tecnologia da Informação em autarquia, e dá outras providências. 24 de agosto de 2001. D. O. U. de 27.8.2001. https://www. dje.tj.sp.gov.br/cdje/index.do;jsessionid=8FE724C5FFB619C48EFA038ACBECDED2.cdje1

Joel Timoteo Pereira, Novas Tecnologias na Justiça, en 40 Anos de política de justiça em Portugal (Rui Guerra da Fonseca, Conceição Gomes, Maria de Lurdes Rodrigues, Pedro Magalhães, Nuno Garoupa eds., Almedina, 2017).

Leí 11.419 de 2006. Sobre a informatização do proceso judicial; altera a ley. 5869 de 11 de janeiro de 1973 - código de proceso civil; e da outras providências. D.O.U. 20/12/2006 (Brasil).

Ley 26.685 de 2011. De Utilización de Medios Electrónicos y Digitales en la Justica Nacional. B. O. 7/07/2011 (Argentina).

Ley 270 de 1996. Estatutaria de la administración de Justicia. 7 de marzo de 1996. D. O. 42.745 (Colombia).

Ley 527 de 1999. Por medio de la cual se define y reglamenta el acceso y uso de los mensajes de datos, del comercio electrónico y de las firmas digitales, y se establecen las entidades de certificación y se dictan otras disposiciones. 21 de agosto de 1999. D. O. 43.673 (Colombia).

Ley 8.687 de 2008. Ley de Notificaciones Judiciales. 29 de enero del 2009. Gaceta n. 20 (Costa Rica).

Medida Provisoria n. ${ }^{\circ}$ 2.200-2 de 24 de agosto de 2001, de la Presidencia de la República Brasilera. http://www.plan alto.gov.br/ccivil_03/MPV/Antigas_2001/2200-2.htm 
Poder Judicial, Sistema de Consulta en Línea, Autenticación con Firma Digital (Costa rica). https://pjenlinea.poderjudicial.go.cr/SistemaGestionEnLineaPJ/Publica/wfpIngresarFirma.aspx

Poder Judicial, Sistema de Consulta en Línea, Ingreso consulta privada (Costa rica). https://pjenlinea.poder-judicial. go.cr/SistemaGestionEnLineaPJ/Publica/wfpIngresar.aspx

Portaria n. ${ }^{\circ} 114 / 2008$, [Ministério da Justiça] "Regula vários aspectos da tramitação electrónica dos processos judiciais”, 6 de fevereiro (Portugal) https://data.dre.pt/eli/port/114/2008/02/06/p/dre/pt/html

Portaria n. ${ }^{\circ}$ 1538/ 2008 [Ministério da Justiça] "Altera e republica a Portaria n. ${ }^{\circ} 114 / 2008$, de 6 de Fevereiro, que regula vários aspectos da tramitação electrónica dos processos judiciais", de 30 de dezembro (Portugal). https://data.d re.pt/eli/port/1538/2008/12/30/p/dre/pt/html

Portaria n. 280/2013, [Ministério da Justiça] "Regula vários aspetos da tramitação eletrónica dos processos judiciais",26 de agosto (Portugal). https://data.dre.pt/eli/port/280/2013/08/26/p/dre/pt/html

Portaria n..$^{\circ}$ 65A/2010, [Justiça] “Terceira alteração à Portaria n..$^{\circ}$ 1538/2008, de 30 de Dezembro, que altera e republica a Portaria n. ${ }^{\circ} 114 / 2008$, de 6 de Fevereiro, que regula vários aspectos da tramitação electrónica dos processos judiciais", 29 de Janeiro. (Portugal). https://data.dre.pt/eli/port/65-a/2010/01/29/p/dre/pt/html

Portaria n. ${ }^{\circ}$ 93/2019, [Ministério da Justiça], Procede à alteraçao da Portaria n. 267/2019, de 20 de setembro. 28 de março de 2019. D.R 62. (Portugal). https://data.dre.pt/eli/port/93/2019/03/28/p/dre/pt/html

Registro de Usuarios Web, Argentina, https://sau.pjn.gov.ar/ruw/gwtInit.gwt\#_

Resoluçao 185/2013 [Conselho Nacional de Jutiça] Institui o Sistema Processo Judicial Eletrônico - PJe [DJE/CNJ] 241. 18 de descimbre de 2012. (Brasil)

Resolução 234/2016. [Conselho Nacional De Justiça] Institui o Diário de Justiça Eletrônico Nacional (DJEN), a Plataforma de Comunicações Processuais (Domicílio Eletrônico) e a Plataforma de Editais do Poder Judiciário. [DJE/CNJ] 120. 14 de Julião de 2016. (Brasil).

Resolución 2998/2014 [Corte Suprema de Justicia de la Nación]. Con el objeto de evitar desiguales en las causas donde participe letrados no videntes, se los deberá eximir, cuando así lo requieran del correspondiente certificado de discapacidad. 6 de noviembre de 2011. B.O 33.005 (Argentina).

Tomás Marino, El Sistema de Notificaciones por Medios Electrónicos en el Poder Judicial de la Nación, la acordada 31/11 y sus complementarias (Abeldo Perrot, 2014). https://www.academia.edu/14442981/El_Sistema_de_N otificaciones_por_Medios_Electr\%C3\%B3nicos_en_el_Poder_Judicial_de_la_Naci\%C3\%B3n_La_Acordad a_31_11_de_la_CSJN_y_sus_complementarias

\section{Notas}

* Artículo de investigación. Este artículo no tuvo ningún tipo de financiación.

1 Se advierte que el escrito no pretende profundizar en los beneficios aportados por el empleo de las nuevas tecnologías en cada uno de los países estudiados, sino una revisar su normativa y sus características más destacadas. Los beneficios que aporta la tecnología al proceso, particularmente a las notificaciones judiciales, ameritan un estudio independiente. No obstante, en la parte final del documento y a manera de conclusión, se introduce el tema a través de unas sucintas reflexiones.

2 Se resalta que la experiencia respecto a las notificaciones electrónicas en el ámbito judicial en la República de Argentina tiene una connotación nacional y otra provincial. Por lo anterior, algunas provincias como Buenos Aires, Mendoza, Córdoba, Neuquén, etc., tienen su propia reglamentación. Sin embargo, en este escrito no nos centraremos en el desarrollo provincial.

3 Ley 26.685 de 2011. De Utilización de Medios Electrónicos y Digitales en la Justica Nacional. B. O. 7/07/2011 (Argentina). El Art.2 deja a cargo de "La Corte Suprema de Justicia de la Nación y el Consejo de la Magistratura de la Nación, de manera conjunta, la reglamentación y utilización de los medios electrónicos en el poder judicial”.

4 Acordada n. $31 / 2011$ [Corte Suprema de Justicia de la Nación]. Sistema de Notificaciones por Medios ElectrónicosAplicación. 4 de abril de 2012. B. O. 32.371 (Argentina).

5 El sistema encuentra su antecedente en la Resolución 385/2005 del Consejo de la Magistratura del Poder Judicial de la Nación. Para más detalles, véase: Tomás Marino, El Sistema de Notificaciones por Medios Electrónicos en el Poder Judicial de la Nación, la acordada 31/11 y sus complementarias (Abeldo Perrot, 2014). 
Las otras Acordadas son: 31/2011, 3/2012, 8/2012, 29/2012, 14/2013, 15/2013, 24/2013, 35/2013, 36/2013, 38/2013, 43/2013, 2/2014, 6/2014 y 11/2014. De estas, se resaltan las Acordadas 3/2012, 29/2012,35/2013,36/2013, $38 / 2013,11 / 2014$ y $3 / 2015$.

7 Acordada n. ${ }^{\circ}$ 3/2012 [Corte Suprema de Justicia de la Nación]. Sistema de Notificaciones por Medios ElectrónicosAplicación. 4 de abril de 2012. B. O. 32.371 (Argentina).

8 Acordada n. 29/2012 [Corte Suprema de Justicia de la Nación]. Notificaciones por Medios Electrónicos. Obligatoriedad. 25 de febrero de 2013. B. O. 32.587 (Argentina).

9 Acordada n. ${ }^{\circ} 35 / 2013$ [Corte Suprema de Justicia de la Nación]. Establecer que el Sistema de Notificaciones por Medios Electrónicos Reglamentado por la Acordada 31/2011 es de aplicación obligatoria. 4 de octubre de 2013. B. O. 32.737 (Argentina).

10 Acordada n. ${ }^{\circ} 36 / 2013$ [Corte Suprema De Justicia De La Nación]. Establecer que el Sistema de Notificaciones por Medios Electrónicos Reglamentado por Acorada 31/2011 será de aplicación con relación a las notificaciones que deben efectuarse en las causas radicadas ante la jurisdicción prevista en el artículo 117 de la Constitución nacional, con arreglo a lo dispuesto en la Acordada 51/73. 4 de octubre de 2013. B. O. 32.737 (Argentina).

11 Acordada n. ${ }^{\circ}$ 38/2013 [Corte Suprema de Justicia de la Nación]. Sistema de Notificaciones por Medios Electrónicos. Obligatoriedad. Apruébese el plan de difusión y capacitación. 17 de octubre de 2013. B. O. 32.745 (Argentina).

12 Acordada n. ${ }^{\circ} 11 / 2014$ [Corte Suprema de Justicia de la Nación]. Sistema de Notificaciones Electrónicas, Defensores y Fiscales. 7 de mayo de 2014. B.O. 32.878 (Argentina) y Acordada N.․ 3/2015 [Corte Suprema de Justicia de la Nación]. Aprobar pautas ordenatorias para garantizar el adecuado y actualizado uso de los nuevos sistemas informáticos que se encuentran implementados, así como el correcto tratamiento de las particulares características que involucran a las partes y otros intervinientes en el proceso. 25 de febrero de 2015. B. O. 33.077 (Argentina).

13 Resolución 2998/2014 [Corte Suprema de Justicia de la Nación]. Con el objeto de evitar desiguales en las causas donde participe letrados no videntes, se los deberá eximir, cuando así lo requieran del correspondiente certificado de discapacidad. 6 de noviembre de 2011. B.O 33.005 (Argentina).

14 El enlace al sitio se puede encontrar aquí: http://www.csjn.gov.ar

15 Registro de Usuarios Web, Argentina. https://sau.pjn.gov.ar/ruw/gwtInit.gwt\#_

16 Debe anotarse que el anexo I de la Acordada 31/2011 no precisa si el cómputo es en días hábiles o naturales, por lo que se sigue la presunción del artículo 28 del Código Civil Argentino, según la cual "en los plazos que señalasen las leyes o los tribunales, o los decretos del gobierno, se comprenderán los días feriados, a menos que el plazo señalado sea de días útiles, expresándose así". Así las cosas, cuando el artículo 2 del Anexo I de la Acordada 31/2011 hable de “(...) A tales fines se otorgará un plazo de treinta días cuyo vencimiento habilitará el procedimiento de baja del registro efectuado por el letrado, en cuyo caso deberá reingresar nuevamente la información requerida", se debe entender que ese plazo es de días naturales. Acordada n. ${ }^{\circ}$ 31/2011 [Corte Suprema de Justicia de la Nación]. Sistema de Notificaciones por Medios Electrónicos- Aplicación. 4 de abril de 2012. B. O. 32.371 (Argentina).

17 Tomás Marino, El Sistema de Notificaciones por Medios Electrónicos en el Poder Judicial de la Nación, la acordada 31/11 y sus complementarias, At 8 (Abeldo Perrot, 2014). "La carga de constituir domicilio electrónico es regulada por la Acordada 31/11 solo para las causas en trámite ante la CSJN. Sin embargo, la aplicación del sistema - y con ello, la carga de constituir domicilio electrónico - ha sido ampliada en las distintas fases de implementación del SNE de conformidad con las seis acordadas dictadas con posterioridad (Confr. Acordadas No 3/12, 29/12, 35/13, 36/13, 38/13 y 43/13 de la CSJN)".

18 Acordada n. ${ }^{\circ}$ 31/2011 [Corte Suprema de Justicia de la Nación]. Sistema de Notificaciones por Medios ElectrónicosAplicación. 4 de abril de 2012. [B. O.] 32.371. 4 de abril de 2012. (Argentina). Artículo 3

19 Código Procesal Civil y Comercial [CPCCN]. Ley 17.454 de 1981.Art. 152 (Argentina). Las actuaciones y diligencias judiciales se practicarán en días y horas hábiles, bajo pena de nulidad. Son días hábiles todos los del año, con excepción de los que determine el Reglamento para la Justicia Nacional. Son horas hábiles las comprendidas dentro del horario establecido por la Corte Suprema para el funcionamiento de los tribunales. Sin embargo, respecto de las diligencias que los jueces, funcionarios o empleados deben practicar fuera de la oficina, son horas hábiles las que median entre las siete y las veinte. Para la celebración de audiencias de prueba, las cámaras de apelaciones podrán declarar horas hábiles, con respecto a juzgados bajo su dependencia y cuando las circunstancias lo exigieren, las que median entre las siete y las diecisiete o entre las nueve y las diecinueve, según rija el horario matutino o vespertino. Ver también el artículo 156. "Los plazos empezarán a correr desde la notificación y si fuesen comunes, desde la última. No se contará el día en que se practique esa diligencia, ni los días inhábiles".

20 Tomás Marino, op. cit., At 13.

21 Véase Acordada n. $31 / 2011$ [Corte Suprema de Justicia de la Nación]. Sistema de Notificaciones por Medios Electrónicos- Aplicación. 4 de abril de 2012. B. O. 32.371 (Argentina). Anexo II. Arts. 4, 7 y 8.

22 Antes de la Ley 11.419 de 2006 existían algunos movimientos tendentes a la implementación de los medios electrónicos en Brasil por parte de los tribunales federales especiales, como el sistema "e-Proc" que contribuyó a que se expidiera la ley 
en el año 2006. También el tribunal regional federal da $4^{\mathrm{a}}$ Região, implemento con base en el artículo 154 del antiguo Código Procesal Civil, un Diario Electrónico, experiencia que también sería recogida en el año 2006 por la ley. Véase Demócrito Reinaldo Filho, Comunicação eletrônica de atos processuais na Lei no 11.419/06 (2019). El texto de la ley está disponible en: http://www.riaej.com/node/269

23 Por nombrar algunos, e-saj (Tribunal de Justicia del estado de Ceará, Sao Pablo, Santa Catarina, entre otros); projudi (poder judicial del estado de Mato Grosso, Paraná, Bahía, entre otros); e-STF (Supremo Tribunal Federal de Brasil); eSTJ (Tribunal Superior de Justicia de Brasil), entre otros. El Consejo Nacional de Justicia, conocedor de la existencia de esos sistemas, emitió las resoluciones 12/2006 y 3 de 2013, fijando unas pautas que buscan la interoperabilidad de los mismos.

24 Resoluçao 185/2013 [Conselho Nacional de Jutiça] Institui o Sistema Processo Judicial Eletrônico - PJe [DJE/CNJ] 241. 18 de descimbre de 2012. (Brasil).

25 Código Processo Civil [CPC]. Lei 13.105 de 2015 (Brasil).

26 Resolução 234/2016. [Conselho Nacional De Justiça] Institui o Diário de Justiça Eletrônico Nacional (DJEN), a Plataforma de Comunicações Processuais (Domicílio Eletrônico) e a Plataforma de Editais do Poder Judiciário. [DJE/ CNJ] 120. 14 de Julião de 2016. (Brasil).

27 Leí 11.419 de 2006. Sobre a informatização do proceso judicial; altera a ley. 5869 de 11 de janeiro de 1973 - código de proceso civil; e da outras providências. D.O.U. 20/12/2006 (Brasil). Art 40 “Os tribunais poderão criar Diário da Justiça eletrônico, disponibilizado em sítio da rede mundial de computadores, para publicação de atos judiciais e administrativos próprios e dos órgãos a eles subordinados, bem como comunicações em geral".

28 La normativa que trata de los procesos de certificación es la Medida Provisoria n. $2.200-2$ de 24 de agosto de 2001, de la Presidencia de la República Brasilera que puede ser consultada en el sitio web: http://www.planalto.gov.br/ccivil_03 /MPV/Antigas_2001/2200-2.htm, Asimismo, el sitio oficial de la ICP-Brasil es: https://www.iti.gov.br/icp-brasil

29 A modo de ejemplo, se puede consultar el DJE del Tribunal de Justicia de São Paulo, en: https://www.dje.tj.sp.gov.br/c dje/index.do;jsessionid=8FE724C5FFB619C48EFA038ACBECDED2.cdje1

30 Diario de Justicia Electrónico, Conselho Nacional de Justiça (CNJ) (s. f.). Este se puede consultar en: http://www.cnj.ju s.br/dje/djeletronico?visaoId=tjdf.djeletronico.comum.internet.apresentacao.VisaoDiarioEletronicoInternetPorData

31 Ley 270 de 1996. Estatutaria de la administración de Justicia. 7 de marzo de 1996. D. O. 42.745 (Colombia).

32 Íd. Artículo 95.

33 Ley 527 de 1999. Por medio de la cual se define y reglamenta el acceso y uso de los mensajes de datos, del comercio electrónico y de las firmas digitales, y se establecen las entidades de certificación y se dictan otras disposiciones. 21 de agosto de 1999. D. O. 43.673 (Colombia). Artículos 5,6,12.

34 Acuerdo n. ${ }^{\circ}$ 1591/02 [Consejo Superior de la Judicatura] por el cual se establece el sistema de información de gestión de procesos y manejo documental (Justicia XX). 24 de octubre de 2002. (Colombia)

35 Acuerdo n. 3334/2006 [Consejo Superior de la Judicatura]. Por el cual se reglamenta la utilización de medios electrónicos e informáticos en el cumplimiento de las funciones de administración de justicia. 2 de marzo de 2006 (Colombia).

36 Código de Procedimiento Administrativo y de lo Contencioso Administrativo [CPACA]. Ley 1437/2011.18 de enero de 2011 (Colombia). Art. 186 “todas las actuaciones judiciales susceptibles de surtirse en forma escrita se podrán realizar a través de medios electrónicos, siempre y cuando en su envío y recepción se garantice su autenticidad, integridad, conservación y posterior consulta, de conformidad con la ley. La autoridad judicial deberá contar con mecanismos que permitan acusar recibo de la información recibida, a través de este medio".

37 Código General del Proceso [CGP]. Ley 1564 de 2012. 12 de julio de 2012 (Colombia).

38 Acuerdo n. ${ }^{\circ}$ 9269/2012 [Consejo Superior de la Judicatura]. Por el que se expide el Plan Estratégico Tecnológico de la Rama Judicial. 27 de febrero de 2012 (Colombia). Acuerdo n. ${ }^{\circ}$ 9269/12 [Consejo Superior de la Judicatura] por el que se expide el Plan Estratégico Tecnológico de la Rama Judicial. 27 de febrero de 2012. (Colom.)

39 El PET tiene 5 ejes fundamentales: 1) Modelo de expediente electrónico; 2) Justicia en Red; 3) Gestión de la información; 4) Gestión del Cambio; y 5) Uso de las TIC para la formación judicial y ciudadana.

40 Acuerdo n. ${ }^{\circ}$ 9810/2013 [Consejo Superior de la Judicatura]. Por el cual se adopta el plan de acción para la implementación del Código General del Proceso. 25 de abril de 2013 (Colombia).

41 Germán Gómez Rojas, Alianza por la transformación de la justicia con Expediente Electrónico Judicial. Noticias Corte Suprema de Justicia (2019).

42 Herney de Jésus Ortiz Montacada, Notificaciones, Traslados y Avisos, en El Juicio por Audiencias en la Jurisdicción de lo Contencioso Administrativo: Guías Procesales Casos Típicos, At. 118 (María Cristina Gómez Isaza ed., 2012). "La norma busca dejar en libertad a los demandantes particulares de escoger si quieren ser o no notificados por medio electrónico, al igual que a sus apoderados, no siendo igual para las entidades públicas quienes obligatoriamente deben proporcionar la dirección electrónica”. 
43 A su vez, el artículo 291 contempla la opción de que si el sujeto procesal, es una persona natural y le ha suministrado al juez la dirección de correo electrónica, se podrá hacer la notificación personal por este medio.

44 Véase artículos 291del CPG y 199 de CPACA.

45 Obligación que está latente hasta que se dé la completa implementación del expediente judicial electrónico en Colombia.

46 Un ejemplo de una entidad que presta este servicio es Certicámara a través del servicio Certimail. Para mayor información acceder a: https://web.certicamara.com/productos_y_servicios/Plataformas_Cero_Papel/42-Correo_Electrónico_C ertificado_-_Certimail

47 El Manual Para Uso del Sistema de Gestión de Procesos Judiciales. Justicia XXI WEB, puede ser consultado en: https: //disajcucuta.files.wordpress.com/2017/01/3-manual-uso-jxxi-web.pdf

48 El Sitio web oficial del Consejo Superior de la Judicatura es: https://www.ramajudicial.gov.co/web/consejo-superiorde-la-judicatura

49 Ley 8.687 de 2008. Ley de Notificaciones Judiciales. 29 de enero del 2009. Gaceta n. 20 (Costa Rica).

50 El documento responde al No 2748-19 y fue una iniciativa del Magistrado Luis Guillermo Rivas Lóaciga, coordinador de la Comisión de Notificaciones, para darle cumplimiento a la recomendación emitida por la Auditoria Judicial en el informe 227-71-SAO-201 y la recomendación de la dirección de planificación para el II circuito judicial. Acta de Consejo Superior n. ${ }^{\circ} 025 / 2019$ [Consejo Superior del Poder Judicial]. DOCUMENTO n. ${ }^{\circ}$ 2748-19 "por medio de la cual se adjunta el documento denominado: 'Guía Práctica de Comunicaciones Judiciales', para que la misma sea aprobado por los integrantes del Consejo Superior”.

51 Ley 8.687 de 2008. Ley de Notificaciones Judiciales. 29 de enero del 2009. Gaceta n. 20 (Costa Rica). Art.3

52 Ley 8.687 de 2008. Ley de Notificaciones Judiciales. 29 de enero del 2009. Gaceta n. 20 (Costa Rica). Art. 39. "Autorización de cuenta. Para acceder al sistema de notificaciones por correo electrónico, el interesado deberá solicitar, al Departamento de Tecnología de Información del Poder Judicial, que se le acredite la cuenta de correo. La solicitud podrá hacerse en forma verbal con los datos requeridos. El Departamento hará la prueba respectiva y, de confirmarse la entrega, ingresará la cuenta autorizada a la lista oficial. En todo caso, la seguridad y seriedad de la cuenta seleccionada son responsabilidad del interesado".

53 A https://pjenlinea3.poder-judicial.go.cr/vcce.userinterface/

54 Ley 8.687 de 2008. Ley de Notificaciones Judiciales. 29 de enero del 2009. Gaceta n. 20 (Costa Rica). Art. 7. Facultase a la Corte Suprema de Justicia para que, además de las formas de notificar previstas en esta Ley, implemente otras modalidades de notificación, cuando los sistemas tecnológicos lo permitan, siempre que se garantice la seguridad del acto de comunicación, el debido proceso y no se cause indefensión.

55 Véase: Poder Judicial, Sistema de Consulta en Línea, Ingreso consulta privada (Costa rica). https://pjenlinea.poder-jud icial.go.cr/SistemaGestionEnLineaPJ/Publica/wfpIngresar.aspx

56 Véase: Poder Judicial, Sistema de Consulta en Línea, Autenticación con Firma Digital (Costa rica). https://pjenlinea.p oder-judicial.go.cr/SistemaGestionEnLineaPJ/Publica/wfpIngresarFirma.aspx

57 En el siguiente Sitio web: https://pjenlinea2.poder-judicial.go.cr/GIO/frmGIO se puede encontrar una lista de Oficina Centrales de Notificación, con sus respectivos contactos.

58 El Departamento de Tecnología de la Información forma parte del Consejo Superior del Poder Judicial. Para ampliar información puede consultarse el Sitio Web: https://pj.poder-judicial.go.cr/index.php

59 Ley 8.687 de 2008. Ley de Notificaciones Judiciales. 29 de enero del 2009. Gaceta n. ${ }^{\circ} 20$ (Costa Rica). Art. 38. Cómputo del Plazo "Cuando se señale un correo electrónico, fax o casillero, la persona quedará notificada al día 'hábil' siguiente de la transmisión o del depósito respectivo. No obstante, todo plazo empieza a correr a partir del día siguiente hábil de la notificación a todas las partes".

60 Circular n. ${ }^{\circ}$ 42-2011 [Corte Suprema de Justicia]. Aplicación del artículo 38 de la Ley de Notificaciones Judiciales (n. ○ 8687).

61 Joel Timoteo Pereira, Novas Tecnologias na Justiça, en 40 Anos de política de justiça em Portugal (Rui Guerra da Fonseca, Conceição Gomes, Maria de Lurdes Rodrigues, Pedro Magalhães, Nuno Garoupa eds., Almedina, 2017).

62 Al aplicativo se puede acceder desde el sitio web: https://www.citius.mj.pt

63 Portaria n. 93/2019, [Ministério da Justiça], Procede à alteraçao da Portaria n. 267/2019, de 20 de setembro. 28 de março de 2019. D.R 62. (Portugal). https://data.dre.pt/eli/port/93/2019/03/28/p/dre/pt/html

64 Portaria n. ${ }^{\circ} 65 \mathrm{~A} / 2010$, [Justiça] “Terceira alteração à Portaria n. ${ }^{\circ}$ 1538/2008, de 30 de Dezembro, que altera y republica a Portaria n. ${ }^{\circ} 114 / 2008$, de 6 de Fevereiro, que regula vários aspectos da tramitação electrónica dos processos judiciais”, 29 de Janeiro. (Portugal). https://data.dre.pt/eli/port/65-a/2010/01/29/p/dre/pt/html

65 Edgar Valles, Prática Processual Civil, 59-60 (10 ed., Almedina, 2019)

66 Para mayor información consultar la guía de preguntas. CITIUS - Magistrados Judiciais, véase: https://www.dgpj.mj.pt /sections/politica-legislativa/anexos/sections/politica-legislativa/anexos/citiusperguntase/downloadFile/file/Doc\%2 0Trab\%20Perguntas\%20\&\%20Respostas\%20site\%20DGPJ\%20\%282\%29.mht?nocache=1 193409549.19 
David Namen Baquero. Notificaciones electrónicas judiciales: una aproximación ...

67 Acordada n. $31 / 2011$ [Corte Suprema de Justicia de la Nación]. Sistema de Notificaciones por Medios ElectrónicosAplicación. 4 de abril de 2012. B. O. 32.371 (Argentina).

\section{Licencia Creative Commons CC BY 4.0}

Cómo citar este artículo: David Namen Baquero, Notificaciones electrónicas judiciales: una aproximación a la reglamentación y uso en algunos paises Iberoamericanos, 69 Vniversitas (2020). https://doi.org/10.11144/Ja veriana.vj69.neja 